\title{
The Military Health Care System May Have the Potential to Prevent Health Care Disparities
}

\author{
Bosny J. Pierre-Louis • Angelo D. Moore • \\ Jill B. Hamilton
}

Received: 21 August 2014 / Revised: 11 October 2014 / Accepted: 24 October 2014 / Published online: 6 December 2014

(C) W. Montague Cobb-NMA Health Institute 2014

\begin{abstract}
Introduction The existence of health disparities in military populations has become an important topic of research. However, to our knowledge, this is the first study to examine health disparities, as related to access to care and health status, among active duty soldiers and their families. Specifically, the purpose of this analysis was to evaluate whether health disparities exist in access to care and health outcomes of patient satisfaction, physical health status, and mental health status according to race, gender, and sponsor rank in the population of active duty soldiers and their family members. Methods In this cross-sectional study, active duty army soldiers and family members were recruited from either one particular army health clinic where they received their health care or from an adjacent shopping center frequented by eligible participants. Data were collected using validated measures to assess concepts of access to care and health status. Statistical analysis, including one-way analysis of variance (ANOVA) was performed to investigate differences in study outcome measures across four key demographic subgroups:
\end{abstract}

Electronic supplementary material The online version of this article (doi:10.1007/s40615-014-0067-6) contains supplementary material, which is available to authorized users.

B. J. Pierre-Louis

Novion Analytics, 7112 Montibillo Pkwy, Durham, NC 27713, USA

A. D. Moore $(\square)$

Center of Nursing Science \& Clinical Inquiry, Womack Army

Medical Center, 2817 Reilly Road, Fort Bragg, NC 28310, USA

e-mail: angelo.d.moore.mil@mail.mil

J. B. Hamilton

Johns Hopkins University, 525 N. Wolfe Street, Baltimore,

MD 21205, USA race, gender, sponsor rank, and component (active soldier or family member).

Results A total of 200 participants completed the study questionnaires. The sample consisted of $45.5 \%$ soldiers and $54.5 \%$ family members, with $88.5 \%$ reporting a sponsor rank in the category of junior or senior enlisted rank. Mean scores for access to care did not differ significantly for the groups race/ethnicity $(p=0.53)$, gender $(p=0.14)$, and sponsor rank $(p=0.10)$. Furthermore, no significant differences were observed whether respondents were active soldiers or their family members $(p=0.36)$. Similarly, there were no statistically significant subgroup (race/ethnicity, gender, sponsor rank, or component) differences in mean patient satisfaction, physical health, and mental health scores.

Discussion In a health equity system of care such as the military health care system, active duty soldiers and their family members did not experience disparities in access to care or in important health outcomes of patient satisfaction, physical health status, or mental health status.

Keywords Health disparity · Military health care system · Access to care $\cdot$ Rank $\cdot$ Race $\cdot$ Patient satisfaction $\cdot$ Health status $\cdot$ Socioeconomic status

\section{Introduction}

The military health care system is a health equity system that grants equal access and comprehensive health care benefits to a diverse population of beneficiaries. Equity in health means that there is an equal opportunity to be healthy for all populations; whereby, resources are distributed and processes and policies are designed to equalize the health outcomes of disadvantaged groups with more advantaged groups [1]. Not only do members enjoy equal access to prevention and treatment services but also the standards of care are the same for all 
members, independent of geographic regions [2]. Thus, it would be reasonable to expect little or no health disparities among beneficiaries of this universal health care system whose main distinguishing feature is ubiquitous access to health care by its members. While health equity relates to attaining the highest level of health for all people, health disparity is the existence of a greater or lesser particular health outcome for one or more populations closely linked to nonhealth care system factors such as social, economic, and/or environmental disadvantages [3].

The existence of health disparities among military populations has been the object of important research, especially because individuals affected by health disparities are more likely to experience adverse health outcomes such as greater burden of illness and disability, higher morbidity and mortality rates, and increased behavioral risks [4-6]. In nonmilitary populations, inequalities in socioeconomic status, race/ethnicity, age, access to care, gender, sexual identity or orientation, religious affiliation, geographical locations, housing, and education are just a few social determinants that have been identified in health disparities research [3]. However, studies assessing health disparities in the military equal access health care system found no significant influence of sociocultural factors such as race/ethnicity in the reduction of key health outcomes in studies focused on the alleviation of disparities in colon cancer [7], lung cancer [8], prostate cancer [9], congestive heart failure [10], and breast cancer [11]. In at least one study of oral health outcomes in military patients, little to no disparity was found between black and white dental military patients, and the oral health of the military population was found to be generally better than that of the civilian population [12].

A number of studies conducted among nonmilitary populations have uncovered evidence of residual or even increasing inequalities in health outcomes, based on gender [13], socioeconomic status [14], and race [15]. In a mixed sample of veteran and civilian populations, women were more likely than men to report general medical and mental distress and higher lifetime anxiety and depressive disorders [16]; nevertheless, there is evidence to suggest female veterans experience potentially modifiable barriers that contribute to delayed health care or unmet health care needs [17, 18]. Research conducted in active duty army female soldiers outside of reproductive issues is limited [19]. However, more frequent deployments and expanded roles of women during combat operations while in the military suggest a growing need for research to examine gender inequities in health outcomes.

In nonmilitary populations, education and income are important factors in ones' ability to obtain health insurance and access to health care [20]. In military populations, a soldier's rank establishes socioeconomic status, since rank determines income and other benefits associated with that particular rank. Military ranks consist of enlisted soldiers and commission officers with commissioned officers outranking all enlisted soldiers. There is a significantly larger percentage of ethnic minorities in the army (with similar percentages in other branches of the military) that are enlisted soldiers (87.4\%) compared to commissioned officers (12.6\%) [21], so race/ ethnicity might be important to evaluate disparities in health care in military populations. Although access to health care is a benefit regardless of rank, there is evidence that racial disparities exist among military populations.

Race has been found to be a contributor of unequal health outcomes in a number of chronic illnesses such as PTSD diagnosis and care [4, 22], cardiac care [23, 24], laparoscopic cholecystectomy [25], carotid artery imaging [26], and breast carcinoma survival rates [27] among nonmilitary populations. Also of note are the existence of racial disparities in uterine cancers that persist between blacks and whites, even with equal access to health care in the DOD health system [28]. The findings from this research appear to suggest the existence of widening health disparities, especially among veterans from various racial/ethnic groups. However, the majority of these studies have focused on older veterans and their family members that have retired or are no longer active duty members.

Research studies evaluating health outcomes for ethnic minorities and their family members on active duty are scant, and most only have the active duty service members. For example, in a study of 284,850 active duty air force members aged 21 or older, the researchers found evidence of significant disparities based on race/ethnicity in a host of chronic conditions such as hypertension, dyslipidemia, asthma, and diabetes [29]. In all chronic conditions, the prevalence was higher for non-Hispanic blacks. Inequalities in health outcomes have been persistent among military populations as evident from studies that have evaluated this topic among veteran populations [4, 30, 31]. The existence of disparities among veteran populations is puzzling since the majority of this population is in receipt of health care from equity-based centers.

Disparities in health care experienced among these veteran populations have been attributed to carry-over effects from a highly unequal civilian health system prior to military enlistment $[29,32,33]$. Preliminary health risks seem to continue after enrollment, but ethnic groups often receive more equitable care under TRICARE than in the nation as a whole [34]. These studies on health inequities have primarily focused on race and failed to use a more realistic multifaceted approach to the study of health disparities. In addition, the majority of research studies assessing health disparities in military populations have targeted veteran populations and ignored those individuals who are actively serving and their family members.

Therefore, what appears lacking is a more comprehensive look at this problem beyond race, but incorporating other factors such gender, military rank, and component (whether 
active duty soldier or active duty family member). This study is intended to fill this gap. To our knowledge, this is the first study to investigate simultaneously active duty participants or their families' perception of access to care and health disparities from the triple standpoint of patient satisfaction, physical health status, and mental health status, and across various demographic subgroups. We hypothesize that, due to the inner workings of the military health care equity system, participants, regardless of their gender, race, component, and rank would hold similar perceptions of access to care and would not differ in terms of their satisfaction with the health care system and their health status.

\section{Materials and Methods}

\section{Data Collection}

This study is part of a larger study that evaluated individual patient characteristics and health care provider communication behaviors to consider when implementing of the PatientCentered Medical Home model within the military health care system. The study's primary purpose was to examine the relationships between individual patient characteristics (including demographics), communication behaviors, and key health outcomes such as patient satisfaction and health status (physical and mental health) $[35,36]$.

The study protocol was approved by the Institutional Review Board at the larger army medical center responsible for the conduct of research at the study clinic. After obtaining informed consent, participants were given the study questionnaire and a $\$ 20$ gift card upon completion. All participants provided informed consent, and the study investigators adhered to all the policies for protection of human subjects as prescribed in 45 CFR 46.

\section{Theoretical Framework}

To evaluate the multiple-dimensional nature of conditions that impede or facilitate the use of health care services, a modified version of Andersen's Behavioral Model for Health Services Use (Fig. 1) was used to guide this study [37]. Evaluation of individual characteristics other than demographics was the first step in building the model, and these results are published elsewhere [35]. The second step in building a more comprehensive model was evaluating health behaviors related to communication during the process of receiving medical care. Finally, a third dimension of the model building was to evaluate the effects of demographic characteristics on access to care and health outcomes (patient satisfaction, physical health, and mental health). In this paper, we focus on this third dimension of model building.
Sample

Eligible participants for this study had to be (1) an active duty army soldier or family member, (2) $\geq 18$ years old, (3) able to speak English, (4) not under the influence of alcohol, (5) free from apparent cognitive impairment, and (6) eligible to receive care at this particular military health care clinic. In total, 200 eligible participants, who agreed and consented to be in the study, are included in this analysis.

Data were collected using self-administered questionnaires. The questionnaires contained previously validated and reliable measures that assessed concepts related to individual characteristics (access to care, mistrust, and spirituality), communication behaviors (patient-provider communication, communications, and interpersonal treatment), and health outcomes (patient satisfaction, physical health status, and mental health status). Demographic data such as age, education, gender, component (soldier or family member), sponsor rank, assigned clinic (within the larger eligible clinic), approximate number of appointments in the past year, number of months assigned to the study clinic, self-reported race/ ethnic group, and whether assigned a nurse case manager were collected in a manner to ensure participant anonymity and confidentiality. The focus of this analysis is the evaluation of the effects of selected demographic variables (gender, race/ethnicity, component, and sponsor rank) on perceived access to care and selected health outcomes (patient satisfaction, physical health status, and mental health status).

\section{Variables}

\section{Demographic Factors}

Demographic variables, including gender, race/ethnicity, component, and sponsor rank (which served as a proxy for socioeconomic status) categories were collected on each study participant. The following categories were used to describe race/ethnicity: Caucasian/White, African American/Black, Latino/Hispanic, Asian, Pacific Islander, or other. Sponsor rank (of the active duty soldier) comprised of junior enlisted, senior enlisted, warrant officer, junior officer, and field grade officer. Finally, component identified whether a given participant was an active duty soldier or active duty family member.

\section{Access to Care}

Access to care was measured using the Perceived Access to Health Services scale which assessed the individual's ability to access medical care in respect to cost, convenience, and feasibility [38]. The 10-item scale had 5 responses ranging from 1 (strongly disagree) to 5 (strongly agree). Sample items are listed in the Appendix. Several items were reverse coded, and all items were summed with higher scores indicating a 
Fig. 1 Conceptual model adapted from Andersen's Behavioral Model for Health Services Use

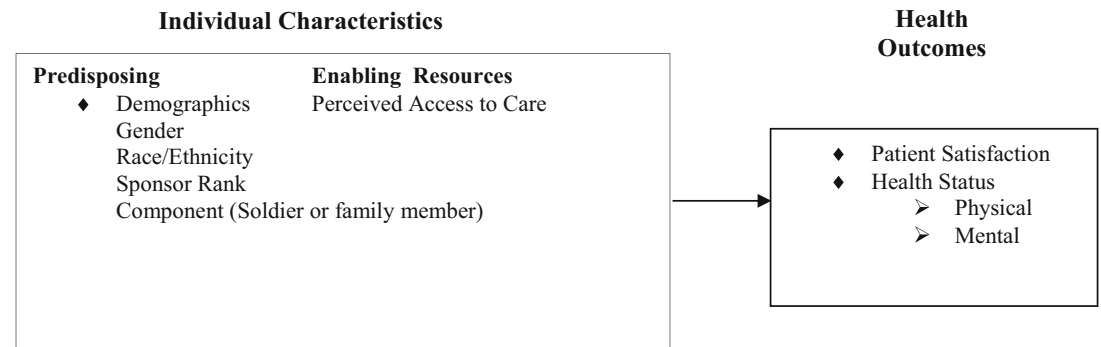

higher degree of perceived access to care. Cronbach's alpha in this study was 0.76 .

\section{Outcome Variables}

Patient satisfaction was measured using a 15-item Patient Satisfaction Within the Health Care System scale which accessed satisfaction with wait times, time spent with providers, information received, quality of care, and cost of care [39]. This scale had five responses ranging from 1 (very dissatisfied) to 5 (very satisfied). Sample items are listed in the Appendix. All items were summed with higher scores indicating a greater degree of patient satisfaction. Cronbach's alpha for this sample was 0.93 .

Health Status was measured using the 12 -item SF-12v2 ${ }^{\circledR}$ which assesses physical health and mental health status. Ten items in this instrument have five responses ranging from 1 (all of the time) to 5 (none of the time), and the remaining two items have three responses ranging from 1 (yes, limited, a lot) to 3 (no, not limited at all). Sample items are listed in the Appendix. QualityMetric. Inc. software was used to score the instrument and generate two summary scores - a physical composite score (PCS) and a mental composite score (MCS). Cronbach's alphas were 0.86 for PCS and 0.83 for MCS.

\section{Data Analysis}

Descriptive statistics consisting of means and standard deviation (SD) for continuous variables and counts and percentages for categorical variables were employed to summarize the demographic characteristics of study participants. A series of one-way analyses of variance (ANOVAs) were then conducted in order to examine the relationship between demographic variables (gender, race/ethnicity, sponsor rank, and component) and access to care. Similar analyses were repeated to examine mean differences in these demographic subgroups as related to access to care, patient satisfaction, physical health, and mental health. All tests of hypothesis were two-tailed, and a $p$ value $\leq 0.05$ was considered statistically significant. As this study was hypothesis-generating, no adjustment for multiplicity was done. Analyses were carried out using the SAS Software (SAS Institute; Cary, NC).
A power analysis was conducted based on addressing the primary objectives of the larger study which included these demographic factors. The calculated sample size required for the larger study was 200 to account for the four demographic variables (gender, component, sponsor rank, and race/ethnicity) and 15 other variables for the larger study; therefore, a separate power calculation for this exploratory portion of this study was not calculated. The sample size was based on a significance level (alpha) of 0.05 , power 0.88 , medium effect size 0.15 , and a dropout rate of $10 \%$.

\section{Results}

Sample Characteristics

Overall, 200 participants enrolled in the study. The mean $( \pm \mathrm{SD})$ participant age was $29( \pm 7.2)$ years, with a high proportion of participants ( $77 \%$ ) younger than 35 years. Of the total sample, $122(61.9 \%)$ were female, $58.5 \%$ white, $17.5 \%$ African American, $10 \%$ Latino/Hispanic, and $6 \%$ Asian. Active duty soldiers made up $45.5 \%$ of the sample, but the majority was active duty family members (54.5\%). The sponsor ranks most prominently represented were junior enlisted $(46 \%)$ and senior enlisted (42.5\%). All collected sociodemographic characteristics of the study population are reported in Table 1.

\section{Access to Care}

Table 2 displays the distribution of perceived access to care by gender, race/ethnicity, component, and sponsor rank. Although there was a slightly higher mean score for access to care among females, there were no statistically significant differences across gender $(p=0.14)$ in the ANOVA model. The mean scores were also generally similar across race/ ethnicity $(p=0.53)$, component $(p=0.36)$, and sponsor rank $(p=0.10)$ in the ANOVA model.

\section{Health Outcomes}

Three key health outcomes were examined and tested for differences across demographic subgroups. These outcomes 
Table 1 Demographic characteristics of study participants

\begin{tabular}{|c|c|}
\hline Characteristic & $\begin{array}{l}\text { No. of Participants } \\
(\%)\end{array}$ \\
\hline Total study sample & $200(100 \%)$ \\
\hline \multicolumn{2}{|l|}{ Age (Years) } \\
\hline $18-24$ & $69(34.5)$ \\
\hline $25-34$ & $85(42.5)$ \\
\hline $35-44$ & $42(21.0)$ \\
\hline$>=45$ & $4(2.0)$ \\
\hline Age, Mean (SD) & $28.8(7.17)$ \\
\hline \multicolumn{2}{|l|}{ Gender } \\
\hline Male & $78(39.0)$ \\
\hline \multicolumn{2}{|l|}{ Active Duty - 74} \\
\hline \multicolumn{2}{|l|}{ Family Member - 4} \\
\hline Female & $122(61.0)$ \\
\hline \multicolumn{2}{|l|}{ Active Duty - 17} \\
\hline \multicolumn{2}{|l|}{ Family Member - 105} \\
\hline \multicolumn{2}{|l|}{ Race } \\
\hline Caucasian/White & $117(58.5)$ \\
\hline African American/Black & $35(17.5)$ \\
\hline Latino/Hispanic & $20(10.0)$ \\
\hline Asian & $12(6.0)$ \\
\hline Pacific Islander & $1(0.5)$ \\
\hline Other & $14(7.0)$ \\
\hline Missing & $1(0.5)$ \\
\hline \multicolumn{2}{|l|}{ Years of Education } \\
\hline 9-12 years & $86(43.0)$ \\
\hline $12-15$ years & $77(38.5)$ \\
\hline$>=16$ years & $37(18.5)$ \\
\hline Years of education, Mean (SD) & $13.6(1.93)$ \\
\hline $\begin{array}{l}\text { No. of medical appointments in a year, Mean } \\
\text { (SD) }\end{array}$ & $9.0(12.33)^{\mathrm{a}}$ \\
\hline \multicolumn{2}{|l|}{ Component } \\
\hline Active Duty (AD) Soldier & $91(45.5)$ \\
\hline AD Family Member & $109(54.5)$ \\
\hline \multicolumn{2}{|l|}{ Sponsor Rank } \\
\hline Junior Enlisted (E1-4) & $92(46.0)$ \\
\hline Senior Enlisted (E5-8) & $85(42.5)$ \\
\hline Warrant Officer (W1-4) & $5(2.5)$ \\
\hline Company Grade Officer (O1-3) & $11(5.5)$ \\
\hline Company Grade Officer (O1-3) & $7(6.4)$ \\
\hline Field Grade Officer (O4-6) & $6(3.0)$ \\
\hline \multicolumn{2}{|l|}{ Assigned clinic (within the larger clinic) } \\
\hline Family Practice & $111(55.5)$ \\
\hline Troop Medical Clinic & $83(41.5)$ \\
\hline Aviation Medicine Clinic & $3(1.5)$ \\
\hline Warrior Transition Unit Clinic & $3(1.5)$ \\
\hline \multicolumn{2}{|l|}{ Months of care at assigned clinic } \\
\hline$<12$ months & $92(46.0)$ \\
\hline $12-24$ months & $58(29.0)$ \\
\hline$>24$ months & $49(24.5)$ \\
\hline
\end{tabular}

Table 1 (continued)

\begin{tabular}{ll}
\hline Characteristic & $\begin{array}{l}\text { No. of Participants } \\
(\%)\end{array}$ \\
\hline $\begin{array}{l}\text { Missing } \\
\text { Having a Nurse Case Manager? }\end{array}$ & $1(0.5)$ \\
No & $180(90.0)$ \\
Yes & $20(10.0)$
\end{tabular}

$S D$ Standard Deviation

${ }^{\text {a }}$ When the 17 participants who reported having $\geq 20$ appointments a year and 5 participants who had missing data for this variable were removed from the sample, the remaining population $(n=178)$ had a marked difference in the mean and standard deviation 5.8 (4.6)

were patient satisfaction, physical health status, and mental health status. Patient satisfaction scores were highest among females (57.4 \pm 12.1$)$, Latinos/Hispanics $(59.6 \pm 12.3)$, AD family members $(57.7 \pm 12.3)$, and warrant officers $(62.6 \pm$ 8.73). No statistically significant association was detected between any of the four demographic factors and patient satisfaction ( $p=0.08$ for gender, $p=0.30$ for race/ethnicity, $p=0.06$ for component, and $p=0.27$ for sponsor rank). Table 3 presents the relationship between the demographic factors of interest and patient satisfaction.

Table 2 Summary of access to care scores by gender, race, component, and sponsor rank

\begin{tabular}{|c|c|c|}
\hline Characteristic & $\begin{array}{l}\text { Access to care summary } \\
\text { Mean (SD) }\end{array}$ & $p$ value $^{\mathrm{a}}$ \\
\hline Gender & & 0.14 \\
\hline Female & $37.8(6.51)$ & \\
\hline Male & $36.4(6.33)$ & \\
\hline Race & & 0.53 \\
\hline African American/Black & $36.7(7.68)$ & \\
\hline Asian & $38.7(5.37)$ & \\
\hline Caucasian/White & $37.4(6.28)$ & \\
\hline Latino/Hispanic & $38.4(6.00)$ & \\
\hline Pacific Islander ${ }^{\mathrm{b}}$ & $43.0(\mathrm{n} / \mathrm{a})$ & \\
\hline Other & $35.2(6.42)$ & \\
\hline Component & & 0.36 \\
\hline AD Family Member & $37.7(6.42)$ & \\
\hline Active Duty Soldier & $36.8(6.51)$ & \\
\hline Sponsor Rank & & 0.10 \\
\hline Company Grade Officer (O1-3) & $40.8(5.27)$ & \\
\hline Field Grade Officer (O4-6) & $40.0(8.12)$ & \\
\hline Junior Enlisted (E1-4) & $37.4(6.43)$ & \\
\hline Senior Enlisted (E5-8) & $36.3(6.39)$ & \\
\hline Warrant Officer (W1-4) & $40.6(6.69)$ & \\
\hline
\end{tabular}


Table 3 Summary of patient satisfaction scores by gender, race, component, and sponsor rank

\begin{tabular}{llc}
\hline Demographic characteristic & $\begin{array}{l}\text { Patient satisfaction score } \\
\text { Mean (SD) }\end{array}$ & $p$ value $^{\mathrm{a}}$ \\
\hline Gender & & 0.08 \\
$\quad$ Female & $57.4(12.10)$ & \\
Male & $54.5(10.47)$ & 0.30 \\
Race & & \\
Caucasian/White & $55.9(10.62)$ & \\
African American/Black & $58.1(13.73)$ & \\
Latino/Hispanic & $59.6(12.30)$ & 0.06 \\
Asian & $55.0(11.10)$ & \\
Pacific Islander & $49.0(\mathrm{n} / \mathrm{a})$ & \\
Other & $51.9(12.69)$ & \\
Component & & \\
AD Family Member & $57.7(12.25)$ & \\
Active Duty Soldier & $54.6(10.49)$ & \\
Sponsor Rank & & \\
Company Grade Officer (O1-3) & $61.3(7.06)$ & \\
Field Grade Officer (O4-6) & $61.3(12.88)$ & \\
Junior Enlisted (E1-4) & $55.5(10.32)$ & \\
Senior Enlisted (E5-8) & $55.9(13.03)$ & \\
Warrant Officer (W1-4) & $62.6(8.73)$ & \\
\hline
\end{tabular}

${ }^{\mathrm{a}} p$ value from an ANOVA models relating each factor to patient satisfaction

${ }^{b}$ There was only one Pacific Islander enrolled in the study. This subject was lumped together with the Asian subgroup in the analysis

Health status scores using physical and mental health indices revealed no significant correlates for gender, race, or sponsor rank (Tables 4 and 5). Higher scores indicate better health. While physical health status scores (Table 4) were numerically higher for males (50.2 \pm 9.79$)$, active duty soldiers (50.0 \pm 9.4$)$, and company grade officers ranks $(54.8 \pm 5.7)$, no statistically significant differences were observed ( $p=0.49$ for gender, $p=0.56$ for race, $p=0.60$ for component, and $p=0.19$ for sponsor rank).

Similarly, we found no differences in mean mental health status scores among the different subgroups (Table 5). The highest mean mental health status scores were achieved by females $(50.2 \pm 9.67)$, Latino/Hispanics (50.6 \pm 8.96$)$, active duty family members $(50.4 \pm 9.89)$, and company grade officers (52.8 \pm 7.58$)$; however, all $p$ values from the ANOVA tests were not statistically significant $(p=0.24$ for gender, $p=$ 0.42 for race, $p=0.18$ for component, and $p=0.34$ for sponsor rank). Additional analyses were conducted to test for possible differences in mean mental health status scores among gender and whether a soldier or family member. We found no statistical difference $(p=0.4)$ in mean mental health scores for active duty female soldiers $(48.11 \pm 18.3)$ and active duty family member females $(50.48 \pm 9.6)$. Due to the sparse sample size for active duty family member males $(n=4)$, we could not conduct reliable hypothesis testing. However, the mean mental health status scores for active duty male family members $(48.11 \pm 18.3)$ and active duty male soldiers $(48.39 \pm 11.6)$ were numerically similar.

\section{Discussion}

A major strength of this study lies in the simultaneous focus on access to care and three distinct health outcomes across different sociodemographic factors. Previous research studies have sought to illuminate the health disparities in various races/ethnicities, but none has so far embarked on a comprehensive appraisal of examining gender, race/ethnicity, using sponsor rank as a proxy for socioeconomic status for active duty army soldiers and their family members.

Overall, this analysis suggests no significant differences in perceived access to health care, patient satisfaction, and health status (physical, mental) across gender, race/ethnicity, component (soldier or family member), and sponsor rank. One highlight is that recipients of care from this equity health care system (universal health care) did not experience health disparities in patient outcomes related to patient satisfaction, physical health status, or mental health status due to differences in race/ethnicity, gender, socioeconomic status (as measured using sponsor rank) or component (active duty army soldier or active duty family member).

Another key take-away is that universal coverage in the military health care system could contribute to a reduction of health disparities carried over from an unequal civilian health care system, especially among women and various races/ ethnicities in minority and vulnerable populations. This is consistent with a longitudinal study with US Navy personnel $(n=1,137)$ where researchers examined changes in patterns of health care use over time following entry in the military health care system [40]. The researchers found that there was a significant increase in the use of preventive services compared to their use of health care services prior to entry into the military.

While research studies focus on military veteran populations, investigators need to make the distinction among these populations, and avoid the "Veteran Soup" which seems to plague many studies. Although a military veteran is anyone who has served in the past or currently serving in the armed forces, all veterans are not equal as it relates to health care eligibility, location of care, access to care, and age. In particular, the army is divided into active duty, reserve or national guard, and retirees. Although the reserve and national guard are separate entities, they are grouped together here for simplicity as it relates to health care access and benefits. Active 
Table 4 Summary of Physical Component Scores by Gender, Race, Component and Sponsor Rank

\begin{tabular}{|c|c|c|}
\hline Demographic Characteristic & $\begin{array}{l}\text { Physical component summary (PCS) } \\
\text { Mean (SD) }\end{array}$ & $p$ value $^{\mathrm{a}}$ \\
\hline Gender & & 0.49 \\
\hline Female & $49.2(9.21)$ & \\
\hline Male & $50.2(9.79)$ & \\
\hline Race & & 0.56 \\
\hline Caucasian/White & $50.1(9.72)$ & \\
\hline African American/Black & $47.1(8.87)$ & \\
\hline Latino/Hispanic & $49.7(9.58)$ & \\
\hline Asian & $48.4(10.04)$ & \\
\hline Pacific Islander ${ }^{\mathrm{b}}$ & $65.5(\mathrm{n} / \mathrm{a})$ & \\
\hline Other & $50.9(7.11)$ & \\
\hline Component & & 0.60 \\
\hline AD Family Member & $49.3(9.48)$ & \\
\hline Active Duty Soldier & $50.0(9.40)$ & \\
\hline Sponsor Rank & & 0.19 \\
\hline Company Grade Officer (O1-3) & $54.8(5.70)$ & \\
\hline Field Grade Officer (O4-6) & $46.5(5.31)$ & \\
\hline Junior Enlisted (E1-4) & $50.5(9.51)$ & \\
\hline Senior Enlisted (E5-8) & $48.3(9.62)$ & \\
\hline Warrant Officer (W1-4) & $49.8(11.50)$ & \\
\hline
\end{tabular}

${ }^{\mathrm{a}} p$ value from an ANOVA models relating each factor to physical health scores

${ }^{\mathrm{b}}$ There was only one Pacific Islander enrolled in the study. This subject was lumped together with the Asian subgroup in the analysis

Table 5 Summary of Mental Health Scores by Gender, Race, Component and Sponsor Rank

\begin{tabular}{|c|c|c|}
\hline Demographic Characteristic & $\begin{array}{l}\text { Mental Component Summary (MCS) } \\
\text { Mean (SD) }\end{array}$ & $p$ value $^{\mathrm{a}}$ \\
\hline Gender & & 0.24 \\
\hline Female & $50.2(9.67)$ & \\
\hline Male & $48.4(11.87)$ & \\
\hline Race & & 0.42 \\
\hline Caucasian/White & $50.4(10.00)$ & \\
\hline African American/Black & $47.9(13.03)$ & \\
\hline Latino/Hispanic & $50.6(8.96)$ & \\
\hline Asian & $47.2(8.34)$ & \\
\hline Pacific Islander $^{\mathrm{b}}$ & $25.5(\mathrm{n} / \mathrm{a})$ & \\
\hline Other & $47.8(11.63)$ & \\
\hline Component & & 0.18 \\
\hline AD Family Member & $50.4(9.89)$ & \\
\hline Active Duty Soldier & $48.4(11.35)$ & \\
\hline Sponsor Rank & & 0.34 \\
\hline Company Grade Officer (O1-3) & $52.8(7.58)$ & \\
\hline Field Grade Officer (O4-6) & $49.2(11.86)$ & \\
\hline Junior Enlisted (E1-4) & $48.7(10.53)$ & \\
\hline Senior Enlisted (E5-8) & $50.3(10.82)$ & \\
\hline Warrant Officer (W1-4) & $41.9(12.03)$ & \\
\hline
\end{tabular}

${ }^{a} p$ value from an ANOVA models relating each factor to mental health scores

${ }^{\mathrm{b}}$ There was only 1 Pacific Islander enrolled in the study. This subject was lumped together with the Asian subgroup in the analysis 
duty members serve full-time, live on or near military installations, receive the majority of their health care free in state-ofthe-art military treatment facilities or in nonmilitary health care facilities for only minimal cost with the focus on "Combat Readiness" through prevention and acute care, and $91 \%$ are $<41$ years old $[2,21]$.

Reserve or national guard members are inactive unless called or volunteered to serve on active duty for a defined period of time (one weekend a month, 2 weeks a year, or longer extended periods of time). They do not live on military installations unless activated for extended periods or their spouse is an active duty member, rely on nonmilitary health care based on TRICARE or their civilian employer's health plan and do not receive free health care in military treatment facilities unless on active duty status or family member of active duty spouse, and $47 \%$ are $>31$ years old $[21,41]$.

Retirees are those that served at least 20 years or medically retired due to limiting medical conditions, do not live on or may not live near a military installation, may or may not receive care at military treatment facilities (based on local policies and space availability), normally receive care in Veteran Health Administration (VA) or nonmilitary health care facilities based on TRICARE or other civilian health policies with a focus on prevention and chronic conditions and illnesses, and are normally $>40$ years old $[41,42]$. As indicated, all veterans are not the same in relation to health care eligibility, access and location of health care, focus of care, and age; yet, studies do not differentiate between the groups of veterans which could allow others to put results in a better context as it relates to health disparities.

This study suggests for active duty army soldiers and their family members that there were no perceptions of disparity in accessing health care services or health disparities in patient satisfaction, physical health status, and mental health status according to race/ethnicity, gender, socioeconomic status, or whether a soldier or family member. This equity system is associated with a lack of health disparities from this population. These findings provide hope that a universal health equity system initiated by the Affordable Care Act may be the catalyst for improving health outcomes for all people and reducing health disparities among civilian disadvantaged groups. Nevertheless, the Affordable Care Act may lack some of the advantages afforded to active duty soldiers and their family members when compared to those receiving care in nonmilitary health care facilities; therefore, the Affordable Care Act may not completely alleviate health disparities.

Access to care, patient satisfaction, and health status are shared both by active duty soldiers and their family members, and these outcomes transcend socioeconomic status. Indeed, a reliable indicator of socioeconomic/income status in the military is rank, as higher ranks translate into a greater income and more prestige. There seems to be an implicit assumption that higher ranking soldiers and their family members would be more likely to receive preferential treatment [43]. Consistent with a study that assessed rank associated with surgical wait times, this assumption was not substantiated in this study [44]. These so-called "privileged" groups did not significantly differ with lower rank participants in their scores pertaining to perceived access to health care, satisfaction, and health status. Overall, the findings of this study are consistent with and support the conclusions by Bagchi (2011) that the impact of preexisting disparities in health outcomes could be mitigated by equal access like the military health care system.

\section{Implications}

In being conscientious of resources and staffing, the Department of Defense created a patient priority system to maintain readiness of service members. While there are patient priorities for getting appointments in military hospitals and clinics with the active duty service members having top priority, this should not be confused with having a health equity system of care. Active duty soldiers and their family members can feel more confident that they are receiving equal access and treatment regardless of race/ethnicity, gender, rank, or being the soldier or a family member. The military system of care for active duty soldiers and their family members provides some sort of standardization that may prevent differentiation in treatment and care which have the potential to induce health care disparities.

Unlike military treatment facilities, Veteran Affairs' Veteran Health Administration provides very little care for active duty army soldiers and their family members. The military health care system has the mission of providing medical support to military operations; therefore, priority of health care go to active duty service members and their family members. Hence, one should not compare health care in the military health care system with care provided to veterans receiving care at Veteran Health Administration facilities where no such mission and priority exists. Although veterans are eligible to receive care in the military health care system, veterans' perception of access to care, satisfaction, physical health status, and mental health status were beyond the scope of this study.

\section{Limitations}

The findings of this study are certainly important, but they need to be interpreted with caution due to possible limitations associated with the study. The sample included in this study is representative of only one active duty army health clinic in the Pacific region of the USA; therefore, the results of this study may not be generalizable to other populations located in different geographical regions. Some of the participants completed study questionnaires in the same clinic where they receive care. As a result of this proximity and the structure 
of the military, some participants might not have been as truthful with responses in fear of retributions.

Although this study was conducted in one particular clinic, the operations of this clinic is consistent with the operations of most army health clinics with the exception of the soldiers and family members receiving care in different subclinics. The operations and setup of this clinic actually adds valuable information to the results of this study, because one can view this as two separate clinics. The family members receive their care in the Family Practice Clinic while the soldiers receive their care in the Troop Medical Clinic. Furthermore, both clinics have the same leadership but different health care providers; yet, there were no significant difference in the health outcomes.

Initially, the study proposal that served as a template for this analysis was powered to evaluate the effect of sociocultural factors on selected health outcomes. Demographic data were analyzed to identify signals of additional effects that analyses of data from the primary endpoint might not have taken into account. As such, the current analysis should be considered exploratory. As a future direction, we recommend to evaluate the same factors in the framework of a well-crafted experimental design that could use longitudinal repeated measures analysis to capture the trends and the various dimensions of the effects of key sociodemographic factors in their relationships with access to health care and key health outcomes while adjusting for potential confounding factors. In addition, future studies should compare retirees and other lower priority entitled beneficiaries in the military health care system with the active duty service members and family members to determine if priority of health care impacts others within the same health care system.

\section{Conclusion}

In a health equity system of care such as the military health care system, active duty army soldiers and their family members did not experience disparities in access to care or in important health outcomes of patient satisfaction, physical health status, or mental health status according to sponsor rank (socioeconomic status), gender, or race/ethnicity. Although soldiers have priority in receiving health care, there were no significant differences in access to care or health outcomes for family members.

Acknowledgments This research study was supported by the TriService Nursing Research Program (grant N11-P05), Uniformed Services University of the Health Sciences. We thank Jessica L. Krusel for her assistance in this research project. We also like to thank the leadership and staff at the clinic and Exchange (formally Army Air Force Exchange Services) for assisting with obtaining all necessary approvals and accommodating sites needed for recruiting participants for this research study.
Conflict of Interest Bosny J. Pierre-Louis, Angelo D. Moore, and Jill B. Hamilton declare that they have no conflict of interest.

Informed Consent All procedures followed were in accordance with the ethical standards of the responsible committee on human experimentation (institutional and national) and with the Helsinki Declaration of 1975, as revised in 2000 (5). Informed consent was obtained from all patients for being included in the study.

Disclaimer The information or content and conclusions do not represent the official position or policy of, nor should any official endorsement be inferred from, the TriService Nursing Research Program, Uniformed Services University of the Health Sciences, Army Medical Department, Department of the Army, Department of Defense, or the US government.

\section{References}

1. Braveman P, Gruskin S. Defining equity in health. J Epidemiol Community Health. 2003;57(4):254-8.

2. Horoho PD, Brock DA. Army Medicine 2020 Campaign Plan, 43rd Surgeon General. Virginia: Unites States Army Medical Department; 2013. p. 1-96.

3. U.S. Department of Health and Human Services. Disparity. 2014 [cited 2014 October 6]; Available from: http://www.healthpeople. gov/2020/about/foundation-health-measures/Disparities.

4. Nayback AM. Health disparities in military veterans with PTSD: influential sociocultural factors. J Psychosoc Nurs Ment Health Serv. 2008;46(6):41-51.

5. Enewold $L$ et al. Racial variation in breast cancer treatment among Department of Defense beneficiaries. Cancer. 2012;118(3):812-20.

6. Egede LE, Dismuke C, Echols C. Racial/Ethnic disparities in mortality risk among US veterans with traumatic brain injury. Am J Public Health. 2012;102 Suppl 2:S266-71.

7. Hofmann LJ et al. Effect of race on colon cancer treatment and outcomes in the Department of Defense healthcare system. Dis Colon Rectum. 2010;53(1):9-15.

8. Zheng L et al. Lung cancer survival among black and white patients in an equal access health system. Cancer Epidemiol Biomarkers. 2012;21(10):1841-7.

9. Johnstone PA et al. Effect of race on biochemical disease-free outcome in patients with prostate cancer treated with definitive radiation therapy in an equal-access health care system: radiation oncology report of the Department of Defense Center for Prostate Disease Research. Radiology. 2002;225(2):420-6.

10. Bagchi AD et al. Treatment and outcomes for congestive heart failure by race/ethnicity in TRICARE. Med Care. 2011;49(5):489-95.

11. Morehead-Gee AJ et al. Racial disparities in physical and functional domains in women with breast cancer. Support Care Cancer. 2012;20(8):1839-47.

12. Hyman JJ et al. The military oral health care system as a model for eliminating disparities in oral health. J Am Dent Assoc. 2006;137(3): 372-8.

13. Doyle L. Gender equity in health: debates and dilemmas. Soc Sci Med. 2000;51(6):931-9.

14. LaVeist $\mathrm{T}$. On the study of race, racism, and health: a shift from description to explanation. Int J Health Serv. 2000;30(1):217-9.

15. Tsai $\mathrm{J}$ et al. The effects of race and other socioeconomic factors on health service use among American military veterans. Psychiatr Q. 2014;85(1):35-47.

16. Grossbard JR et al. Relationships among veteran status, gender, and key health indicators in a national young adult sample. Psychiatr Serv. 2013;64(6):547-53. 
17. Blosnich J, Foynes MM, Shipherd JC. Health disparities among sexual minority women veterans. J Womens Health. 2013;22(7): 631-6.

18. Washington DL et al. Access to care for women veterans: delayed healthcare and unmet need. J Gen Intern Med. 2011;26 Suppl 2:655-61.

19. Trego L, Wilson C, Steele N. A call to action for evidence-based military women's health care: developing a women's health research agenda that addresses sex and gender in health and illness. Biol Res Nurs. 2010;12(2):171-7.

20. Kenik J, Jean-Jacques M, Feinglass J. Explaining racial and ethnic disparities in cholesterol screening. Prev Med. 2014;65:65-9.

21. Department of Defense. 2012 Demographics: profile of the military community. Washington D.C.: Military Community and Family Policy, Office of the Deputy Assistant Secretary of Defense; 2013. p. 1-191.

22. Murdoch M et al. Mitigating effect of Department of Veterans Affairs disability benefits for post-traumatic stress disorder on low income. Mil Med. 2005;170(2):137-40.

23. Ngo-Metzger Q, et al. Cultural competency and quality of care: obtaining the patient's perspective. 2006. The Commonwealth Fund. p. $1-40$.

24. Groeneveld PW, Kruse GB, Asch DA. Variation in cardiac procedure use and racial disparity among Veterans Affairs Hospitals. Am Heart J. 2007;153(2):320-7.

25. Arozullah AM et al. Racial variation in the use of laparoscopic cholecystectomy in the Department of Veterans Affairs medical system. J Am Coll Surg. 1999;188(6):604-22.

26. Conigliaro $\mathrm{J}$ et al. Understanding racial variation in the use of coronary revascularization procedures: the role of clinical factors. Arch Intern Med. 2000;160(9):1329-35.

27. Jatoi I, Becher H, Leake CR. Widening disparity in survival between white and African-American patients with breast carcinoma treated in the U. S. Department of Defense Healthcare system. Cancer. 2003;98(5):894-9.

28. Oliver KE et al. Racial disparities in histopathologic characteristics of uterine cancer are present in older, not younger blacks in an equalaccess government. Gynecol Oncol. 2011;123(1):76-81.

29. Hatzfeld JJ, LaVeist TA, Gaston-Johansson FG. Racial/ethnic disparities in the prevalence of selected chronic diseases among US Air Force members, 2008. Prev Chron Dis. 2012;9:E112.
30. Harris GL. Reducing healthcare disparities in the military through cultural competence. J Health Hum Serv Adm. 2011;34(2):145-81.

31. Edwards R. Widening health inequalities among U.S. military retirees since 1974. Soc Sci Med. 2008;67(11):1657-68.

32. Hatzfeld JJ, Gaston-Johansson FG. Disparities in U.S. Air Force preventive health assessments and medical deployability. Mil Med. 2010;175(1):25-32.

33. Harris GL, Lewis EL, Calloway M. A call to action: increasing health providers in underrepresented populations through the military. $\mathrm{J}$ Health Hum Serv Adm. 2012;35(3):356-410.

34. Bagchi AD. Racial and ethnic health disparities in TRICARE. J Natl Med Assoc. 2009;101(7):663-70.

35. Moore $\mathrm{AD}$ et al. Increasing access to care and reducing mistrust: important considerations when implementing the patient-centered medical home in Army health clinics. Mil Med. 2013;178(3):291298.

36. Moore AD, Hamilton JB, Pierre-Louis BJ. Communication behaviors predict patient satisfaction, physical health status, and mental health status for active duty Army Soldiers and their family members: important considerations when implementing the patient-centered medical home. J Natl Black Nurses Assoc. 2013;24(2):8-16.

37. Andersen RM. National health surveys and the behavioral model of health services use. Med Care. 2008;46(7):647-53.

38. Facione NC, Facione PA. Perceived prejudice in healthcare and women's health protective behavior. Nurs Res. 2007;56(3):175-84.

39. Mishel MH. Cultural and demographic predictors of interaction with the health care system and prostate cancer aggressiveness. In: Project 2. Chapel Hill: University of North Carolina at Chapel Hill; 2003.

40. McWhorter SK et al. Changes in healthcare use across the transition from civilian to military life. Int J Health Plan Manag. 2014;29(2): e186-204.

41. Department of Defense. TRICARE. [cited 201429 July]; Available from: https://www.tricareonline.com. 2014.

42. Veteran Affairs. Veterans Health Administration. [cited 201429 July]; Available from: http://www.va.gov/health/. 2014.

43. MacLean A. The privileges of rank: the peacetime draft and later-life attainment. Armed Forces Soc. 2008;34(4):682-713.

44. Wilson DJ, Crawford DA, Arrington ED. Preoperative wait time for orthopedic surgeries at a military medical center. Mil Med. 2012;177(6):740-4. 